\section{A Study on Mutual Intelligibility \\ between Romance Languages}

Thotagamuwa, T.J. ${ }^{1, *}$

${ }^{1}$ Department of Linguistics, University of Kelaniya, Kelaniya, 11600, Sri Lanka.
Sri Lanka Journal of Social Sciences and Humanities Volume 2 Issue 1, February 2022: 139-147 ISSN: 2773 692X (Online), 27736911 (Print) Copyright: (C) 2021 The Author(s)

Published by Faculty of Social Sciences and Languages, Sabaragamuwa University of Sri Lanka Website: https://www.sab.ac.lk/sljssh DOI: http://doi.org/10.4038/sljssh.v2i1.65

Received: 30 April, 2021, Revised: 26 September, 2021, Accepted: 12 December, 2021.

How to Cite this Article: Thotagamuwa, T.J. (2022). A Study on Mutual Intelligibility between Romance Languages. Sri Lanka Journal of Social Sciences and Humanities, 2(1), 139-147.

\begin{abstract}
Romance languages are the modern languages that evolved from Vulgar Latin languages between the third and eighth centuries. This comes under a subgroup of Italic languages within the Indo-European language family. The five major and mostly spoken Romance languages all over the world are Spanish, Portuguese, French, Italian, and Romanian. The fundamental vocabularies of all the Romance languages were inherited from Latin. Besides, some words shared in Romance languages are not directly from the Latin inheritance, but they are words that were borrowed from the Celtic origin. The main intention of this research is to discover the similarities between the Romance languages not only in the morphological, syntactic, semantic, and phonetic basis but also the vocabulary variations in this language family. By the beginning of the 21st century, 920 million people claimed a Romance language as their mother tongue whilst 300 million people as a second language. In the current global context, at least one language of the Romance language family is studied by a significant number of divergent ethnic groups in different parts of the world. In such a period, where Romance languages are embraced by thousands, the study of linguistic characteristics in terms of mutual intelligibility of Romance languages provides the opportunity to identify the unique features interconnected with each language. Romance methods of forming unfamiliar words are also inherited from Latin origin. For instance, the suffix "-āre" in Latin morphology, which is a part of infinitives, has made the influence for languages such as French, Italian, and Catalan in making verbs. For example, the lexical form of "to plant" in Latin is "plantāre" and similarly "planter" in French, "plantare" in Italian, and "plantar" in Catalan. In conclusion, the Romance languages, which were originated from Latin, have more intelligibility even if they are considered as different languages of different regions at present.
\end{abstract}

Keywords: Indo-European, Intelligibility, Italic Language, Latin, Romance

\section{INTRODUCTION}

Language is a social phenomenon, which has been evolving since the origin of humankind. Based on different geographical, social as well as ethnic diversifications, a number of languages have been brought in certain periods. Though such languages have had their uniqueness and identity, the availability of related characteristics among groups of languages could be witnessed with the continuous flow of time. It was found that the reason for this certain fact was that several languages have been evolving with the influence of a single language class or family. With the facts behind the similarities between languages being revealed, past specialists of language investigated the identity of various languages in the world. This is the stage where the beginning of Comparative Linguistics was marked for the first time. The origin of a certain language acts as the decider of the linguistic features of a certain language, including its structure, style, etc. Each language belongs to a certain origin where it derived from and in each language, there are several languages with derivational similarities. These are known as language families. The specific language family, to which certain languages belong, creates the factors and characteristics to which the languages of its origin differ from other origins of languages.
In the historical journey of language, many languages' origins have been discovered through the studies which were implemented in the fields of Historical and Comparative Linguistics. Among all the significant language families, the Romance language family is considered remarkable not only because it consists of some of the most consequential languages in the world, but also because of the equivalence that the languages of Romance language family bear as a single language origin. The Romance language family began to appear preliminary in the $8^{\text {th }}$ century. A romance language family is a sub-group of Italic languages that belongs to the Indo-European language family. The development of this language family, thus, occurred through the gradual origination of the principal languages of this family of languages. French is considered as one of the first languages in this group of languages which was introduced in the $9^{\text {th }}$ century. Spanish, Italian, Portuguese, Catalan, and Romanian were successively introduced in the $10^{\text {th }}, 12^{\text {th }}, 13^{\text {th }}$, and $15^{\text {th }}$ centuries as the major languages of the Romance language family. Thus, Romance languages became one of the most spoken language varieties in the world because of the unique specialties that could be seen in this specific language fam-

\footnotetext{
* Corresponding author: Tel.: +94 71645 1754; Email: tharindu96jayanath@gmail.com

(iD) https://orcid.org/0000-0002-1719-5567
} 
ily. This is an analytical study that is implemented to investigate the mutual intelligibility between Romance languages to find related linguistic characteristics of the aforementioned languages of this certain language family. Mutual intelligibility is known as the interconnection between languages and dialects which have different speakers, but corresponding or linked linguistic varieties could be effortlessly understood without any naturalness or familiarity with that certain language. Amidst diverse language families, Romance language family has the unique ability to be mentioned as a language family which consists of mutual intelligibility to a greater extent when compared to alternative language families. Every language in the Romance language family originated from Vulgar Latin. Thus, as a consequence, the formation of linguistic classes and categories of each Romance language could be identified intelligible in a considerable manner. These languages bear similarities in the forms of lexicography, syntax, morphology, semantics as well as phonology as a unique language family in the field of Linguistics. Having these resemblances in different linguistic aspects has been able to create support and easement for the learners of Romance languages to acquire these languages without any interventions and on the other hand, various linguistic assets have been offered to the speakers on account of mutual intelligibility of Romance languages. Therefore, Romance languages have been identified as a firm family of languages in the linguistic environment. Resultantly, being a more unique and sophisticated language family, Romance languages signify their importance into a whole advanced level in the aspect of mutual intelligibility between this specific set of universally accepted languages.

\section{LITERATURE REVIEW}

As described by the European Commission (2007), Receptive Multilingualism was identified as one communication strategy that would be worth studying the language. This receptive multilingualism strategy can be used by people from closely related languages. They can communicate with each other using their languages without having to speak each other language. (Oktavia, 2019) Languages, which have been evolving from the same mother language, tend to resemble each other respectively in lexical, morphological, syntactic, and semantic contexts considerably. As some initial studies have shown, in some languages, mutual intelligibility between closely related languages is asymmetric. It can be seen in the language pairs of Spanish and Portuguese as Romance language pair and between Czech and Slovak in the Slavic language branch. It is assumed that the mutual intelligibility occurred based on the Geographical distance. (Oktavia, 2019) Gooskens and Van Heuven (2017), in their recent study which focused on measuring cross-linguistic intelligibility in the Germanic, Romance, and Slavic language groups by using word test, cloze test, and picture matching tasks, found that the functional tests displayed similar patterns of intelligibility, where especially the cloze test and word translation were strongly correlated. The judged intelligibility scores and the results of the six functional tests are presented the intelligibility score per language family, 20\% (Germanic and Romance families) or 30\% (Slavic) different language combinations. However, there was a bit of difference in Romance group, where the scores on the word test were lower than cloze test scores for some groups, especially in spoken words. (Oktavia, 2019) However, even though each member of this Romance language pair is understandable by speakers of the other language, the mutual intelligibility between these two languages is asymmetric. Portuguese speakers can understand Spanish more easily than Spanish speakers can understand Portuguese. According to Oktavia (2019), it is assessed that Portuguese is more complicated than Spanish. Even, it was explained in one of the popular tourist guidebooks (Qebsen \& Biel, 1986) that most Portuguese have a good and natural ability to comprehend spoken Spanish, they know Spanish without exposing the language. Meanwhile, the Spanish can ask questions in Portuguese, but they are unable to understand the response. In an experiment by Jensen (1989), it was found that mutual intelligibility of Spanish and Portuguese in his study involving Brazilian-Portuguese group and Spanish (Latin-American) group. In this study, the results also showed that the Brazilian-Portuguese speakers could understand and comprehend Spanish rather well. Mateus and d'Andrade (2000) stated that Portuguese has similar phonetics to French or Catalan. The pronunciation of Spanish is recognized more closely related to Italian pronunciation (Eddington, 2004). Mutual intelligibility is a great strategy to break down the gap of communication between closely related languages. Speakers from closely related languages tend to communicate by using their native languages, but they can understand each other's language. They can understand each other language without having to learn the other languages. However, some related languages have asymmetric mutual intelligibility. As a Romance language pair, Portuguese and Spanish are understandable for each other's speakers, but the Spanish speakers find it more difficult to understand Portuguese than vice versa, Portuguese speakers can understand Spanish easier. (Oktavia, 2019) some factors lead to this phenomenon. These factors come from both linguistic and non-linguistic factors. The attitude toward language becomes the most important non-linguistic factor that causes the asymmetric. (Oktavia, 2019)

\section{MATERIALS AND METHODS}

Research is a logical and systematic search for new and useful information on a particular topic. (Rajasekar et al., 2006) According to the implementation strategies of this research, this section of the study outlines the research strategy, research approach, research process as well as type of data analysis. The research has taken the form of new research through several existing research were found. The reason for this research to claim a newer appearance than the parallel research related to the field is that the old research mostly focussed on the practical use of language among the speaking communities of the relevant language. Moreover, previous research has been implemented as investigations on the mutual connection between the European languages as a whole. As a result, to this extent in the relevant field of study, a specific linguistic analysis on the mutual intelligibility between languages of the Romance language family has not been launched in the respected field of study. Being a more sophisticated set of languages, Romance language family has its own unique identities. In the attempt to identify this specific feature, every linguistic aspect should be taken into consideration. This research focuses on the five most significant languages in the Romance language family namely French, Italian, Spanish, Portuguese, and Romanian in order to implement the linguistic investigations as well as to achieve a substantial and systematic conclusion related to the objective of this study. Every language in this relevant family of languages claims to possess significant phonological, morphological, lexical, syntactic, as well as semantic specialties. In order to satiate the objectives of the study, this research is implemented under the approach of qualitative 
data collection. The linguistic characteristics of each Romance language are separately identified as the commencing step of the research under phonological, morphological, lexical, and syntactic levels, respectively. As the next step, observation of equivalent linguistic features among the colanguages of the relevant language family is done intending to find the linguistic intelligibility of this certain language family. In this process, each earlier mentioned linguistic aspect will be taken into consideration in order to identify the intelligibility of each level. To begin with, phonological features are studied and analysed to observe to which extent Romance languages are connected in terms of mutual intelligibility. Subsequently, the similarities in the morphological aspect are observed, where the word-formation process of each language is examined. In the study of lexical intelligibility, words used to emphasize different meanings in the language are scrutinized as a unit to identify the lexical intelligibility between the languages of the specific language family. Eventually, the focus is transferred towards the intelligibility at the syntactic level of the relevant languages. As the final stage of the research, identified similar linguistic features are classified according to the relevant subfields of the field of linguistics. Based on the data collection and observation process of the research, this could be considered as an analytical investigation on the intelligible linguistic characteristics of Romance language family. Correspondingly, this research could be considered explanatory research as the relevant study attempts to clarify the type of relationship between several aspects of a certain phenomenon. This research contemplates the mutual relationship between Romance languages which is considered as one of the most significant language families in the linguistic dimension. The application of the relevant research approaches, which are used during the implementation of the research, would contribute to finding complementary knowledge in the relevant field of study.

\section{RESULTS AND DISCUSSION}

Under this section of the research, the results, which were gathered through the data analysis process, are analysed and presented to substantiate the posited concept of the research. This section demonstrates the mutual linguistic features which exist among the languages of the Romance language family. Moreover, the second part of this section focuses on the mutual intelligibility between selected Romance languages separately. The concept of "Mutual Intelligibility" between languages could be identified at different levels as well as different classes of a language. This chapter discusses the aforementioned intelligibility between Romance languages according to the principles related to the subfields in the discipline of linguistics. In this chapter, mutual linguistic features in the phonological, morphological, lexical, syntactic as well as semantic levels would be focussed on identifying the similarities of each Romance language related to each linguistic category. As mentioned earlier, Romance languages have originated from Vulgar Latin. As a result of the Vulgar Latin influence, regardless of possessing unique and differently pronounced phonemes or differently scripted grammatical variations, the foundation of the Romance languages was established with the ascendancy of Latin. By way of explanation, the phonological and morphological aspects of Latin origin contributed to creating the linguistic features of Romance languages. Resultantly, the lexical and morphological characteristics of Romance languages appear to be synonymous to a greater extent. Thus, commanding the proper knowledge of a certain language of the Romance language family has created the opportunity to acquire and comprehend alternative languages of this language family conveniently. Generally speaking, the Romance language family has unique and significant similarities between each language. More approvingly, this specific fact has made the family of Romance languages a sublime classification of languages in the field of linguistics.

\section{Mutual Linguistic Features of Romance Languages}

In general, each language itself claims to have a standard strategy for forming the basic linguistic structures of the language. To put it in other words, each language possesses a unique set of phonemes, morphemes, and lexemes which decide the systematic nature of the language. Languages in the Romance language family feature different systematic approaches in forming linguistic classes of the relevant languages. More importantly, the specialty of the linguistic classes of the Romance language family is that the methods and rules of the form present to be resembling a certain extent as a result of originating from the same source of language which is Vulgar Latin. Therefore, in this section of the research, the mutual linguistic features of Romance language family are particularized under the respective linguistic categories of a language as mentioned below:

1. Phonetic Intelligibility

2. Morphological Intelligibility

3. Lexical Intelligibility

4. Syntactic Intelligibility

\section{Phonetic Intelligibility}

Phonetics is a significant branch in linguistics, which studies the generation of sounds of language from a scientific perspective. Being originated from Vulgar Latin, Romance languages claim to have a unique system of sounds distinctive to each language. This has occurred as several changes related to the sound system of Vulgar Latin developed without adapting the same sound system directly from Vulgar Latin in order to create a uniquely significant sound system in each language. Phonetic intelligibility is the similarities between the sounds of each language in the Romance language family. Regardless of being originated from the corresponding source, a fully equivalent system of sounds could not be identified among the relevant languages because of different causes related to phonological influence, such as articulation, lexicon, stress, and prosodic variations. Nevertheless, it is discernible that diverse intelligibility of sounds exists within the languages of this specific language family under various phonetic principles. The below table demonstrates the mutually intelligible phonetic features between the languages of the Romance language family. 
Table 1: PHONETIC INTELLIGIBILITIES BETWEEN ROMANCE LANGUAGES

\begin{tabular}{|c|c|c|c|c|c|}
\hline Phonetic Category & French & Italian & Spanish & Portuguese & Romanian \\
\hline \multirow[t]{2}{*}{ Semivowels } & j & j & j & j & j \\
\hline & w & w & w & w & w \\
\hline \multirow[t]{6}{*}{ Suprasegmentals } & - & - & - & - & - \\
\hline & - & 1 & - & & \\
\hline & & 1 & , & $\begin{array}{l}1 \\
1\end{array}$ & i \\
\hline & - & & & & \\
\hline & $\varepsilon$ & $\varepsilon$ & - & $\varepsilon$ & - \\
\hline & $\varnothing$ & - & - & - & $\varnothing$ \\
\hline \multirow[t]{3}{*}{ Vowels } & $y$ & $\mathrm{y}$ & - & - & $\mathrm{y}$ \\
\hline & $\tilde{a}$ & - & - & - & \\
\hline & $\tilde{\varepsilon}$ & - & - & - & $\tilde{\varepsilon}$ \\
\hline \multirow[t]{3}{*}{ Consonants } & $\mathrm{n}$ & $n$ & $n$ & $n$ & $n$ \\
\hline & $\eta$ & $\eta$ & $\eta$ & - & $\eta$ \\
\hline & 3 & - & - & 3 & 3 \\
\hline
\end{tabular}

In the observation of phonetic intelligibility between Romance languages, the following phonetic categories were investigated.
1. Semivowels
2. Suprasegmentals
3. Vowels
4. Consonants

In the field of Phonetics, the definition of semivowels is given as speech sounds of vowels quality, which are used as consonants. In each of the five Romance languages, which are examined in this study, both the palatal approximant semivowel [j] and the labio-velar approximant semivowel [w] were observed to have existed in the phonetic chart. Thus, the availability of the above-named semivowels in each language could be identified as significant phonetic intelligibility.

Suprasegmentals were the succeeding phonetic feature that was observed in identifying phonetic intelligibility. Suprasegmentals, also known as prosodic features, are the phonetic features inclusive of stress, tone, and intonation. In the examination of prosodic features of each Romance language, several suprasegmentals were identified to be available in each language, whilst several prosodic features were particularly limited to a certain number of languages in the relevant language family. The syllable boundary or the syllable break [.] appeared in French, Italian, Spanish, Portuguese, and Romanian phonetic charts. As a result of this certain fact, the syllable break was identified as a phonetically intelligible feature between each of the five languages. Italian, Portuguese, and Romanian were the three languages where the secondary stress symbol [,] was identified. The primary stress symbol ['] was encountered to be available in four of the five languages, namely Italian, Spanish, Portuguese, and Romanian. Accordingly, in the aspect of the suprasegmental known as 'syllable break', every language was entirely phonetically intelligible to each other. In contrast, Italian, Portuguese, and Romanian were identified as phonetically intelligible in the observation of secondary stress symbol whilst the primary stress symbol was recognized as an intelligible feature in four languages, and Italian, Spanish, Portuguese, and Romanian were the particular languages. Considerably, in the suprasegmental feature viewpoint, phonetic intelligibility was discovered to be available at a considerable level among the relevant languages of the Romance family.
As the next phase, vowels were the phonetic feature that was used to measure the mutual phonetic intelligibility between the languages of the Romance family. In this process, several phonetically unique vowels were examined apart from the basic and common set of vowels in language. Amidst the vowel symbols observed, the open-mid front unrounded or low-mid front unrounded vowel $[\varepsilon]$ was observed to be available in the phonetic alphabet of French, Italian, and Portuguese. This phonetic feature was intelligible between the three above-stated languages. This specific vowel is used in French language as an oral vowel and in Portuguese, it is known as a stressed vowel. The vowel [ $\varnothing]$ was only observed in French and Romanian languages. As a result, this symbol could be exclusively identified as phonetic intelligibility between French and Romanian. The availability of the close front rounded vowel $[y]$ was noticed in the phonetic chart of French, Italian, and Romanian. Therefore, this symbol is phonetic intelligibility between the three mentioned languages. Two vowels in the phonetic chart were unique to the two languages, French and Romanian; ã and $\tilde{\varepsilon}$. In French language, these two vowels are known as 'nasal vowels' and 'non-native vowels' is the term used to name these two vowels in Romanian. Therefore, these two vowels could be identified as a phonetically intelligible feature between French and Romance.

Consonants were the last component that was focused on identifying phonetic intelligibility between the Romance languages. Exclusive of the basic consonants of language, three consonants, which play a significant role in Romance languages, were focussed in this process. The voiced palatal nasal [n] was noticed to be available in French, Italian, Spanish, Portuguese, and Romanian and thus, it could be considered as phonetic intelligibility between the five mentioned languages. The availability of the velar nasal [n] symbol was observed and this specific symbol was found to be phonetically intelligible between French, Italian, Spanish, and Romanian. In finding the intelligibility between the languages of the Romance language family related to the voiced post-alveolar fricative [3], it was marked intelligible between the three languages French, Portuguese, and Romanian.

Noticeably, in the proceeding of recognizing the mutual phonetic intelligibility between the Romance languages, a considerable number of intelligibilities were identified related to various aspects in Phonetics. On that account, it is perceptible that the languages of the Romance language family are mutually intelligible in the aspect of phonetics in a general manner. 


\section{Morphological Intelligibility}

In linguistic terminology, morphology is the internal structure of words. In the attempt to identify morphological intelligibility between Romance languages, different types of morphemes related to each of the Romance languages were observed in the research. In consideration of morphological categories of Romance languages, morphemes related to verbs, adjectives, nouns, and adverbs, as well as tenses, encompass the significance in the relevant field. Through this section of the research, the morphologically intelligible features would be demonstrated which would be assistive in identifying to which extent the languages of the Romance family are inter-related in the aspect of mutual intelligibility. One of the most significant types of morphemes is the morphemes related to verbs and verb formation. Verbs of Romance languages are divided into several categories based on the ending of the relevant infinitives. These could be identified as the infinitive morphemes which decide the verb category and additional variations exercised in verb formation. In other words, the rules of verb formation differ from one verb category to the other based on the infinitive morpheme of the verb of the relevant Romance language.

Table 2: INFINITIVE MORPHEMES OF ROMANCE LANGUAGES

\begin{tabular}{ll}
\hline Infinitive Morpheme & Intelligible Languages \\
\hline er & French, Spanish, Portuguese \\
ar & Spanish, Portuguese \\
ir & French, Spanish, Portuguese \\
\hline
\end{tabular}

According to the above chart, these infinitive morphemes were identified as mutually intelligible features among the languages of the Romance family. The verb ending 'er' could be noticed as a common morpheme that remarks the infinitive form of French, Spanish, and Portuguese. Moreover, regardless of bearing an additional letter, the infinitive morpheme 'ere' in the Italian language could be considered as a morphologically intelligible feature, as it is originated from the same source language. The verb ending ' $a r$ ', which is identifiable in Spanish and Portuguese, could be noticed as a mutual morphological feature. As mentioned earlier, the morpheme 'are' could be morphological intelligibility similar to Spanish and Portuguese, though there can be seen a difference when compared to 'ar' as 'are' also is derived from the source morpheme ' $a r$ ' in Vulgar Latin. In the verb's observation ending 'ir', there is the possibility of proclaiming that the morphological intelligibility between French, Spanish, and Portuguese is quite apparent. More importantly, it could be proclaimed that 'ire' in Italian could be identified as an intelligible feature with French, Spanish, and Portuguese because of originating from the unique source language. Resultantly, based on the morphemes related to the infinitives of each language, the morphological intelligibility between Romance languages is proved to exist considerably.

Pluralization is an important linguistic feature of any language. There are several steps followed in a language in order to make the plural forms of nouns and adjectives major in Romance languages. In pluralization, the fundamental approach is the addition of an inflectional morpheme to the noun based on characteristics and requirements. Romance languages possess a number of morphemes related to pluralization, which are used differently within each language. The inflectional morphemes, which are used in the pluralization process of Romance languages, could be listed as follows.

\section{Table 3: INFLECTIONAL MORPHEMES USED IN PLURALIZATION}

\begin{tabular}{ll}
\hline Inflectional Morpheme & Intelligible Languages \\
\hline $\mathrm{s}$ & French, Spanish, Portuguese \\
$\mathrm{es}$ & Spanish, Portuguese \\
$\mathrm{i}$ & Italian, Romanian \\
$\mathrm{e}$ & Italian, Romanian \\
\hline
\end{tabular}

Based on the data provided in the above table, the usage of inflectional morphemes could be seen in French, Spanish, and Portuguese. This morpheme is mostly used in French, Spanish, and Portuguese. It is used to form the plural of nouns that end with vowels. Thus, this fact could be noticed as a feature that confirms the morphological intelligibility between French, Spanish, and Portuguese. The morpheme 'es' was identified as a common morpheme used in the pluralization process of Spanish and Portuguese. As a matter of fact, 'es' could be considered as a morphologically intelligible feature between Spanish and Portuguese. The use of the inflectional morphemes ' $i$ ' and 'e' were only identified in Italian and Romanian. It could be found as mutual intelligibility related to morphology between Romanian and Italian. Resultantly, morphological intelligibility between certain languages of the Romance language family was recognized to be available to a certain extent.

Considerably, as a consequence of being originated from the identical source language, a number of resemblant morphological features could be identified between the Romance languages. From the indicators of the infinitive forms to the pluralization of nouns adjectives, similar morphological features could be recognized, remarking the proximity of Romance languages. To summarize, Romance language family is a significantly important language family based on the unique morphological intelligibility between languages.

\section{Lexical Intelligibility}

Lexemes represent the basic forms of words in linguistics. Lexical intelligibility signifies the similarity between two or several languages in terms of lexemes. Lexemes derive to a language from certain words or terms of a certain dialect of a language or a different language which is used among several communities. Thus, the influence of Vulgar Latin made a greater impact on the building of the vocabulary of each of the Romance languages. With the influence of the mentioned language origin, the major languages of the Romance family were influenced by the lexical system and structures to a larger extent. As a consequence, a considerable amount of lexemes or words used among the Romance languagespeaking communities were adopted or transferred to the 
relevant languages based on the lexical system of Vulgar Latin. In consideration of the mutual similarity between the major languages of the Romance family, the resemblant lexemes were observed in measuring the mutual lexical intelligibility between Romance languages. In the below table, a list of lexemes, which are considerably similar to each language in this specific language family, has been demonstrated.

Table 4: LEXICAL INTELLIGIBILITY BETWEEN ROMANCE LANGUAGES

\begin{tabular}{lllllll}
\hline Meaning & Term & of & French & Italian & Spanish & Portuguese \\
& Origin & & & & & Romanian \\
Man & homō & homme & uomo & hombre & homem & om \\
New & novum & nouvel & nuovo & nuevo & novo & nou \\
High & altum & - & alto & alto & alto & nove \\
Nine & novem & - & nove & neuve & quatro & - \\
Four & quattro & quatre & quattro & cuatro & - & muyer \\
Woman & domina & - & donna & mujer & - \\
Woman & mulier & - & - & - & femeie \\
Woman & femina & femme & - & can & cão \\
Dog & canem & chien & cane & nostro & nuestro & nosso \\
Our & nostrum & notre & & & nostru \\
\hline
\end{tabular}

The above chart enlists the formation of several lexemes of Romance languages, which belong to various syntactic categories based on the lexemes of the source language. According to the enlisted data, it is visible that the relevant terms, which express a certain meaning in each Romance language, have been based on a single lexeme of the source language.

Ex: homō novum canem nostrum

Each of the above lexemes of Vulgar Latin has acted as the source term in creating the lexemes of the Romance languages. In agreement with the phonetic features of each language, necessary changes have been made in order to give them a unique appearance. In such cases, the mutual lexical intelligibility could be identified between all the five languages of this language family.

In the observation process of lexical intelligibility, there were occasions where lexical intelligibility was only recognized only between certain languages.

Ex:altum novem quatro

According to the above-mentioned instances, several languages have obtained the influence from the source language completely in the formation of lexemes in the relevant languages. For instance, based on the formation of the lexeme related to the term 'altum', Italian, Spanish, and Portuguese were mutually intelligible. Italian, Spanish, Portuguese, and Romanian were recognized as mutually intelligible languages in the formation of lexemes related to the term 'novum.' (Refer table 4.)

In forming lexemes of major languages of Romance family, there were exemplifications where the lexemes were formed with several changes to the term of the language of origin.

Ex: mulier

In the above instance, the lexeme related to the original term was formed by replacing ' $1 \mathrm{i}$ ' of the original term with ' $\mathrm{j}$ ' in Spanish and ' $y$ ' in Portuguese. (Refer Table 4.) Spanish and Portuguese were recognized as mutually intelligible languages according to the remarked alternations.

One of the most significant features, which was identified in observing lexical intelligibility, was that separate languages of the same family have used separate words to form the lexemes of the relevant languages. This is because several equivalent lexemes were available in the source language to express the same meaning.

\section{Ex: mulier femina}

French and Romanian languages have referred to the term 'femina' in Vulgar Latin to form the lexeme in order to establish the relevant meaning whilst 'mulier' was the term which was used in Spanish and Portuguese in forming the lexemes to obtain the supposed meaning. (Refer to table 4.) Thus, French and Romanian were intelligible to each other, and Portuguese and Spanish were related to mutual lexical intelligibility as a result of the approaches followed in forming lexemes.

Considering all the facts presented in this section, it is obvious that there are occasions where each language shares mutual intelligibility and, in contrast, several occasions where only a certain number of languages are observed mutually intelligible in lexical terms. Hence, it is possible to convey the idea that Romance languages are mutually intelligible in the aspect of lexemes.

\section{Syntactic Intelligibility}

Syntax defines the study of the order of words and phrases of a certain language to form proper sentences. In the structural study of the word order or subject-verb agreement of a certain language, several sections are taken into consideration majorly. Such sections are known as syntactic categories in linguistics and under syntactic categories. Nouns, verbs, adjectives, and adverbs are of significant importance, as the mentioned act as the terms which express the intended meaning of a sentence. This section of the research is allocated to focalize the syntactically intelligible features between the Romance languages. Each language of the Romance language family possesses a standard grammatical system. Though each of the languages is considered different languages of different ethnicities, there is visible evidence in order to identify the syntactic intelligibility between the languages of Romance language family as a consequence of originating from the sociolect called 'Vulgar Latin.'

Taking cognizance of Syntax, the most significant component to be assessed is the order of the sentence or to put in other words, the word order of a certain sentence related to numerous languages. The five major languages, which are investigated in this research, feature the words order of subject + verb + object (SVO). Below mentioned sentences exemplify the similarity of the word orders of languages of the Romance language family to each other. 
Table 5: WORD ORDER OF ROMANCE LANGUAGES

MEANING: THE BOY PLAYS FOOTBALL.

\begin{tabular}{lllll}
\hline Sentence & Subject (S) & Verb (V) & Object (O) & Language \\
\hline $\begin{array}{l}\text { Le garçon joue au } \\
\text { Football. }\end{array}$ & Le garçon & joue & au Football. & French \\
$\begin{array}{l}\text { II ragazzo gioco a } \\
\text { calcio. }\end{array}$ & gioco ragazzo & a calcio. & Italian \\
$\begin{array}{l}\text { El niño juega Futbal. } \\
\text { O El niño }\end{array}$ & juega & Futbal. & Spanish \\
$\begin{array}{l}\text { Futebal. } \\
\text { Băiatul joacă Fotbal. }\end{array}$ & Băiatul & joga & Futebal. & Portuguese \\
\hline
\end{tabular}

As it is demonstrated in the above table, it is apparent that each Romance language follows the similar subject+ verb+ object (SVO) order in compiling sentences within the language. This phenomenon has occurred since the word order of Vulgar Latin, the source of origin of Romance languages is formed according to the SVO order.

The placement of adjectives in the major of Syntax considers various rules based on the type of language. Languages in the Romance language family possess a certain set of rules Table 6: PLACEMENT OF ADJECTIVES

\section{MEANING: A CLEVER STUDENT}

\begin{tabular}{lllll}
\hline Adjectival phrase & Article & Noun & Adjective & Language \\
\hline $\begin{array}{l}\text { Un étudiant intelli- } \\
\text { gent }\end{array}$ & Un & étudiant & intelligent & French \\
$\begin{array}{l}\text { Uno studente intelli- } \\
\text { gente }\end{array}$ & Uno & studente & intelligente & Italian \\
$\begin{array}{l}\text { Un estudiante listo } \\
\text { Um estudante inteli- }\end{array}$ & Un & estudiante & inteligente & Spanish \\
$\begin{array}{l}\text { gente } \\
\text { Un student inteligent }\end{array}$ & Un & estudante & inteligente & Portuguese \\
\hline
\end{tabular}

According to the aforementioned instances, it is apparent that the adjective has been placed after the noun in each of the five Romance languages. Therefore, this syntactic feature could be presented as mutual intelligibility between Romance languages in the perspective of Syntax.

Adverbs are a common category of each language that acts as a lexical category to modify adjectives, adverbs, and

Table 7: FORMATION OF ADVERBS

MEANING: PROBABLY

\begin{tabular}{llll}
\hline Adverbial Phrase & Adjective & Inflectional Morpheme & Language \\
\hline probablement & probable & ment & French \\
probabilmente & probabile & mente & Italian \\
probablemente & probable & mente & Spanish \\
provavelmente & provável & mente & Portuguese \\
\hline
\end{tabular}

Considering the adverb formation of each language, it is apparent that the inflectional morpheme, which has been added to the form of the adjective in order to build the adverb, is resemblant to each other. In addition, the inflectional morpheme relevant to each specific language (ment, mente) has been added after the adjective after transferring the adjective into the feminine singular form in all four languages. Accordingly, it is obvious that to decide that the approach of adverb formation is mutual syntactic intelligibility of Romance languages.

Verb formation is considered an essential component in syntactic categories. The formation of verbs is done based on several factors in almost all languages. Time of the action and the doer/subject of the action could be considered as for placing adjectives in a sentence. The specialty of placement of adjectives in the five major Romance languages is that the same approach is followed in this process by each separate language. Below is an example to specify the similarity between the relevant languages in the process of placement of adjectives. verbs. Romance language family owns the potential to be considered as a family of languages which is inclusive of a unique approach of forming adverbs. The lexical or syntactic category known as 'adverbs' could be identified as a special feature in the process of measuring the mutual intelligibility between Romance languages. The example below demonstrates the method of formation of adverbs of the languages of the Romance language family. the most significant characteristics which are considered in the verb formation process of the Romance language family. This is because these two specific features decide the form that the verb should represent within the sentence in each language.

Past tense indicators are a common feature in Romance languages. Each language has a unique past tense ending which is added to the verb stem based on the subject of the action. Mentioned below are the past tense forms of the verbs 'chanter, cantare, and a cânta' successively in French, Italian, and Romanian. 
Table 8: PAST TENSE FORMATION

MEANING YOU SANG.

\begin{tabular}{llll}
\hline Sentence & Auxiliary & Past Participle & Language \\
\hline J'ai chanté. & as & chanté & French \\
(Tu) hai cantato. & hai & cantato & Italian \\
Ai cantat. & ai & cantat & Romanian \\
\hline
\end{tabular}

In taking the above set of examples into observation, it is apparent that each of the three languages (French, Italian, and Romanian) has used the same steps in making the past tense form of a verb. It is thus comprehensible that the auxiliary verb is followed by the subject and the past participle is positioned after the auxiliary. Based on this, it is quite clear that French, Italian, and Romanian languages follow the same method of forming the past tense. Therefore, it could be noticed that the three above-mentioned languages are mutually intelligible in the perspective of verb formation. Apart from these three languages, in Spanish and Portuguese, a different method is applied in forming past tense.

Table 9: PAST TENSE FORMATION

MEANING: YOU SANG.

\begin{tabular}{llll}
\hline Sentence & Subject & Past Tense Verb & Language \\
\hline (Tu) canté. & Tu & canté & Spanish \\
Você cantou. & Você & cantou & Portuguese \\
\hline
\end{tabular}

In the above-stated instance, the past tense verb has been placed after the subject and an auxiliary verb has not been used before the past tense verb. Accordingly, Spanish and Portuguese are syntactically intelligible distinctively when compared to French, Italian, and Romanian in consideration of the attributes of the formation of past tense.

Table 10: FORMATION OF FUTURE TENSE MEANING: I WILL EAT.

\begin{tabular}{lllll}
\hline Sentence & Subjective Pronoun & Verb Stem & Verb Ending \\
\hline Je mangerai. & Je & manger & ai & erò \\
lo mangerò. & lo & mang & é & Italian \\
Me comeré. & Me & comer & ei & Spanish \\
Eu comerei. & Eu & comer & Portuguese \\
\hline
\end{tabular}

The above scripted four languages form their future tense by following the same method. Since this method is resemblant in each language, it could be well argued that the languages French, Italian, Spanish, and Portuguese are mutually intelligible in the aspect of Syntax.

In consideration of the syntactic intelligibility between the languages of the Romance language family, based on the evidence provided in the above discussion of findings, it is completely understandable that numerous intelligibility could be possibly observed between the relevant languages. Hence, it is possible to determine that Romance language family encompasses the syntactic intelligibility between the languages significantly to a considerable extent.

\section{Mutually Intelligible Romance Languages}

As discussed in the above sections, Romance language family is a unique family of languages that claims the specific feature known as 'mutual intelligibility.' In various linguistic aspects, the languages of Romance family were identified to be mutually intelligible as a whole or to have this feature among several languages. This section of the research concentrates on how the languages of this specific language family relate to each other in the perspective of mutual intelligibility. Each language of the Romance family is mutually intelligible with other languages to a considerable extent. This mutual intelligibility occurs to belong to a number of linguistic categories based on the specialties of relevant lan-
Formation of future tense could be identified as a feature of the Romance language family, which established the concept of mutual intelligibility. Formation of the future tense is done according to a systematic method in the Romance languages. The future tense is formed in the languages French, Italian, Spanish, and Portuguese by adding several endings to the verb stem or the infinitive form of the verb. guages. As the final analysis of this section, the level of mutual intelligibility between two separate Romance languages is measured based on the linguistic resemblances of the languages.

The phenomenon 'mutual intelligibility' differs from one language pair to another, depending on the linguistic characteristics that each language possesses. According to the discussion of the results, mutual intelligibility could be identified among the relevant languages in the phonetic, morphological, lexical, and syntactic levels. As a result of being originated from the same source language, it has been proved that each language in the Romance language family shares resemblant linguistic features to a certain extent. The mutual connection between French and Italian could be recognized majorly at the lexical level. Regardless, having a lexical system which identical considerably, as a result of the two different phonetic systems, it is not possible to declare that French and Italian languages are necessarily mutually intelligible. However, there is a considerable level of mutual intelligibility between the two languages in terms of lexical and syntactic characteristics of the two languages.

In consideration of the mutual intelligibility between Spanish and Italian, there is the possibility to mention that Italian and Spanish are considered mutually intelligible to each other in each linguistic aspect. These two Romance languages share a good degree of intelligibility as a consequence of the lexical, phonetic, and syntactic resemblance. 
Furthermore, in comparison with mutual intelligibility between French and Italian, the mutual intelligibility between Spanish and Italian is higher due to the common origin and geographical position. As a substantial degree of mutual intelligibility is not apparent between French and Italian, this condition applies to the level of mutual intelligibility between French and Spanish. This Romance language pair is considered similar to each other in terms of lexical systems which was originated from the Latinate ancestry. French and Spanish share several similarities in the syntactic level conjointly. Yet, it is not considered sufficient in order to mention that French and Spanish are significantly mutually intelligible as a language pair due to several linguistic dissimilarities.

The mutual intelligibility between Spanish and Portuguese is quite comprehendible in the aspect of lexical similarity. Moreover, in terms of pronunciation, this specific pair of languages certainly share similarities to a certain degree. There are several unique similarities between these two languages in Syntax when compared to the other major languages in the Romance family. Thus, it is observable that the mutual intelligibility between Portuguese and Spanish exists to a considerable extent. Concerning mutual intelligibility, the language pair French and Romanian are similar to each other when the lexical similarity is taken into consideration. In addition, certain syntactic similarities could, be identified between these two Romance languages. Consequently, French and Romanian could be considered as a mutually intelligible pair of languages at a particular level. Italian is also considered an intelligible language to Romanian because of the availability of lexical identities to a certain extent. Pronunciation is considered as a fact where the mutual intelligibility between Italian and Romanian could be recognized.

Considering the data discussed in this section, it is obvious that each language claims the concept known as 'mutual intelligibility in terms of diverse linguistic characteristics of each language. Each language of the Romance language family is mutually intelligible to coequal languages in the family, even in a limited number of linguistic features.

\section{CONCLUSION}

Originated in the $8^{\text {th }}$ century preliminarily, Romance language family has been evolving for centuries, contributing to the role of a significant family of languages in the field of Linguistics. In consequence of evolving from the same language origin, mutual intelligibility appeared to be a significant feature of the languages of Romance language family. French, Italian, Spanish, Portuguese, and Romanian are considered the major languages of the Romance family. In the linguistic observation of the degree of mutual intelligibility between the relevant languages, it was observed that mutual intelligibility is a significant feature as each of the languages reinforced diverse linguistic similarities to one another considerably. As each Romance language is claimed to be originated from the language origin of Vulgar Latin, mutual intelligibility was identified in phonetic, morphological, lexical, and syntactic categories majorly. Based on the results of the study, sometimes mutual intelligibility was available between each Romance language. In contrast, frequently, the concept 'mutual intelligibility' was observed exclusively in a certain number of languages. In the study's continuation to discover the language pairs which show resemblance in terms of mutual intelligibility, it was ascertained that each language is mutually intelligible to alternative languages even to a limited extent. In the observation process, it was evident that, without regard to being languages of similar origin, each language was not completely mutually intelligible to another language because of the distinctive features observed in each separate language. Nonetheless, the mutual intelligibility appeared to be extant between each Romance language in terms of diverse linguistic aspects. Accordingly, it is quite apprehensible that each language in the Romance language family has obtained the implication of the Latinate ancestry in forming their distinctive and distinguishing characteristics as a language. In addition to this fact, each language has undertaken significant deviations within the language in order to denote the individuality of the relevant language. Elicited from the above-discussed concepts and presented information, implementation of this research would create pathways for Romance language learners to master the language comprehensively, for researchers of Romance languages to utilize the analysis discussed in this study for further research as literature in a linguistic sense, and for academics in the relevant field to identify the significance of mutual intelligibility as a concept in the respective language family. In summary, as a consequence of the above-mentioned fact, the mutual intelligibility between the languages has occurred to a certain extent, rather than establishing the designated concept of mutual intelligibility comprehensively. In conclusion, it could be potentially accomplished that mutual intelligibility between Romance languages exists to be a significant aspect as a unique component of this specific language family.

\section{REFERENCES}

Eddington, D. (2004). Spanish phonology and morphology. Experimental and quantitative perspectives. Studies in Functional and Structural Linguistics, 53, 197. https://linguistics.byu.edu/faculty/deddingt/EDDINGTON.pdf

Commission of the European Communities (2007). High-Level Group on Multilingualism: final report. Office for Official Publications of the European Communities, Luxembourg. Viewed 23 Dec 2021. http://ec.europa.eu/education/policies/lang/doc/multireport_en.pdf

Goundar, Sam. (2013). Research Methodology and Research Method Methods Commonly Used by Researchers, 2-47. https://www.academia.edu/43187203/Chapter_3_Research_Methodology_and_Research_Method

Gooskens, C., \& van Heuven, V. J. (2017). Measuring cross-linguistic intelligibility in the Germanic, Romance, and Slavic language groups. Speech Communication, 89, 25-36. https://doi.org/10.1016/j.specom.2017.02.008

Jensen, J. B. (1989). On the Mutual Intelligibility of Spanish and Portuguese. Hispania, 72(4), 848-852. https://doi.org/10.2307/343562 Mateus, M., \& d'Andrade, E. (2000). The phonology of Portuguese. Oxford: Oxford University Press.

Oktavia, D. (2019). Understanding New Language: Mutual Intelligibility in Romance Language Pair. Journal of Language Education Development, 2(1), 181-185. http://ejournal.stkip-mmb.ac.id/index.php/pbi/article/view/203/129

Rajasekar, S.P., Philominathan, P., \& Chinnathambi, V. (2019). Research Methodology. Knowledge Management Techniques for Risk Management in IT Projects. https://www.semanticscholar.org/paper/Research-Methodology-Rajasekar-Philominathan/b990144eb89568bd810e296d450eb73cfd7ba665 
